\title{
INTEGRATION OF ICT WITH KNOWLEDGE MANAGEMENT TO Foster Digital INNOVATION: The Case of Bangladesh Public Sector
}

\author{
Md Jahid Hossain Panir, Xu Xiaolin and Mao Zijun \\ College of Public Administration, \\ Huazhong University of Science and Technology, Wuhan, China
}

\begin{abstract}
This paper explores how knowledge management (KM) through information and communication technologies (ICTs) can foster Internet-based digital innovation in the public sector in Bangladesh. A total of twelve semi-structured interviews were conducted with relevant persons in four government organizations. Findings reveal that there are huge unexplored areas where ICT can be utilized for the creation, storage and dissemination of knowledge. By reducing time, cost \& movement ICT-utilized KM can promote ICT-led innovation. The main barrier of ICT-led KM initiatives is the lack of awareness of the government officials. This study is an extension of the previous findings. It contributes significantly to a better understanding of ICT's integration with KM and innovation. It suggests that one of the core functions of ICT in the public offices is to manage knowledge. The paper offers some insights into how in a digital environment, knowledge can be innovatively managed in the public sector organizations.
\end{abstract}

\section{KEYWORDS}

Information and communication technology (ICT), ICT-utilized knowledge management (ICT-KM), ICTbased innovation, public sector, Bangladesh.

\section{INTRODUCTION}

In the digital age, information and communication technology (ICT) has enabled both private and public sector organizations to manage knowledge more innovatively [1]. Studies show that the creation, storage and sharing of both tacit and explicit knowledge can be facilitated through ICT tools, particularly the Internet $[2,3]$. There are also evidences that ICT can be intervened in creating knowledge networks to bring people together virtually and face-to-face for exchanging and building their social knowledge [4, 5]. Although there are several barriers of knowledge management (KM) through ICT, both the researchers and the policy-makers have been embarking on coupling ICT-utilized KM (ICT-KM) with innovation [6]. A report of United Nations Organization (UNO) reveals that even the governments of developing countries have recently made remarkable progress in popularizing ICT for tapping knowledge to bring ICT-led innovation (ICT-I) in the public sector [7]. In spite of the fact that ICT's integration with knowledge management and innovation in government organizations is a current topic of discussion, it lacks in sufficient literature.

The purpose of the research reported in this paper is to contribute to a better understanding of ICT's integration with knowledge management and innovation in the public sector in Bangladesh. This paper aims to investigate how ICT-utilized knowledge management initiatives are promoted towards Internet-based digital innovation. More specifically, in the public sector perspective, it: considers the core areas of the involvement of ICT in managing knowledge; the perception and 
International Journal of Managing Public Sector Information and Communication Technologies (IJMPICT)

Vol. 9, No. 4, December 2018

practices of ICT-based digital innovation; explores the initiatives and mechanisms of how ICTbased knowledge management promotes such innovations; and identifies the factors that affect knowledge management through ICTs.

This paper is divided into six sections. The next section is a literature review that summarizes relevant theories and previous research findings. The following sections first explains the methodology that has been used for the collection \& analysis of data and then outlines the profiles of case organizations. Findings and discussion are outlined in the subsequent sections. Finally, the paper presents conclusions and recommendations for practice and future research.

\section{LITERATURE REVIEW}

The key theories and previous studies on ICT-based knowledge management and innovation in the public sector are summarized in the review of literature.

\subsection{ICT-UTILIZED KNOWLEDGe MANAGEMENT}

'Knowledge' has been a keyword only in the private sector management literature for many years. But recently, researchers have discovered that knowledge is also a very pressing issue in the literature of public sector development informatics because knowledge can be innovatively managed with the power of ICT [8, 9, 10]. Based on the work of Polanyi [11, 12], Nonaka [13] explicates two basic taxonomies of knowledge in organizations: tacit and explicit. Tacit dimension of knowledge is an individual's mental maps, intuition, beliefs, judgment, and viewpoints (cognitive elements) and know-how, skills \& personal experience (technical elements). It is 'a fluid mix of insight from experts', context around the insights as well as experience and values [14]. Explicit knowledge is formal, systematic knowledge that can be codified, written down, and passed on to others in documents [15].

Many organizations have shown interest in managing knowledge as a strategic resource [16]. Alavi and Leidner [3] argue that the aims of the initiatives of managing knowledge are to make knowledge visible, to develop a knowledge-intensive culture and to build a knowledge infrastructure. Knowledge management shows how knowledge can be applied to solving problems and getting things done by utilizing intuition, judgment, and wisdom [17]. Studies reveal that the recent insights of electronic government (e-Government) theories are emphasizing more on knowledge and its exploitation [18, 19]. This 'knowledge-intensive' concept of ICT is further clarified by Heeks [20] who argues that ICT has two intrinsic roles. First, as a process, it performs the handling of data digitally and changes data into information or moves data from sources to recipients. Second, as a facilitator, ICT converts information into knowledge that helps in learning or decision-making.

Therefore, researchers have embarked on understanding why ICT can be utilized for managing knowledge in the public sector domain [21]. As explained by Daft [22], ICT can contribute towards all sets of knowledge process through creating, storing, retrieving, transferring and applying knowledge. Hansen et al. [23] suggest tacit knowledge to be a person-to-person approach. So, ICTs, such as videoconferencing or the telephone, are proved effective at enabling people to transfer tacit knowledge. Explicit knowledge being a people-to-documents approach, allows the reuse of knowledge such as documents.

Studies also show how ICTs can integrate both explicit and tacit knowledge from different perspectives. In this regard, the ICT-KM integration model of Alavi and Leidner [3] plays a key role as it illuminates the insights of ICT-KM studies. From the explicit dimension, they argue that explicit knowledge being an object, can be gathered, stored and transferred through ICTs. This allows the explosion of codified knowledge in the web through Internet technologies. They 
International Journal of Managing Public Sector Information and Communication Technologies (IJMPICT)

Vol. 9, No. 4, December 2018

further justify that when the focus of knowledge is on the access to information, the role of ICT is to offer effective way of searching and retrieving right information. This model of ICT-KM also demonstrates different dimensions of ICT's integration with tacit knowledge. First, if knowledge is a state of knowing and understanding, ICT can provide access to sources of knowledge. Second, if knowledge is the process of applying expertise, the role of ICT is to create links among sources of knowledge in order to widen knowledge flows. Third, if knowledge is the power to influence action, ICT can enhance intellectual capital of organizations through developing individual's competencies and capabilities. Tessier and Dalkir [24] also identify the role of ICT in facilitating the knowledge process, i.e. socialization, externalization, combination and internalization (SECI) of tacit and explicit knowledge as espoused by Nonaka [13]. However, the critics of ICT researchers often undermine the capacity of ICT in managing knowledge [25]. They argue that tacit dimension of knowledge is soft and invisible - for example, a person's insights. Therefore, ICT cannot be fully utilized for accessing all knowledge domains.

Despite these limitations, there is a growing interest to best utilize the intrinsic role of ICT to impact on potential areas of both tacit and explicit knowledge. As explained by Liebowitz and Frank [6], the ultimate goal of KM is the conversion of tacit knowledge into explicit knowledge in order to transfer the capacity of individuals within the organization. The researchers of development informatics strive to justify that this conversion task can be performed by various ICT tools [26]. E-learning, for example, as an ICT-utilized KM tool, allows learners generate and share ideas, explore their thinking, and gain knowledge from domain experts \& other learners and finally results in knowledge transfer [27, 28]. Kim \& Lee [29] show how ICT-mediated Online KM applications emerged as the evolutionary sharing and distribution of knowledge among public sector employees by eliminating geographical barriers. Both policy-makers and researchers now argue that ICT-enabled training mechanism is a key example of public sector ICT-KM [30, 31]. However, empirical evidence shows there is hardly any research findings on employee performance gained from ICT-mediated KM or clear strategy to integrate ICT with KM practices in the public sector [32].

The public sector organizations not only deal with individual or organizational knowledge, but also indulge in social or community knowledge [33]. Bransford [34] highlights how such social components of KM can be harnessed with ICT through facilitating the social networking to learn from the community. Hao et al. [35] show how social media can strengthen knowledge management in the public sector. However, there are often criticisms that the vibrant social media used by the government officials are often used for personal promotion rather than meeting the goals of organizational ICT-KM [36].

\subsection{ICT-Led Innovation In the Public Sector}

ICT-led innovation is a segment of innovations arising from ICT or digital transformation [37, 38]. Researchers argue that before understanding ICT-led innovation, it is also necessary to consider the scope of 'innovation' and 'public sector innovation' (PSI) in general [39, 40]. According to Kanter [41], innovation is a more specialized kind of change - a new idea applied to initiating or improving a product, process, or service. All innovations imply change, but not all changes necessarily introduce new ideas or lead to significant improvements [42].

Public sector innovation is the adoption of new services and processes pertaining to more efficient and effective delivery of public services [43]. Osborne [44] argues that innovation in public sector is important because it could help improve administrative efficiency and effectiveness. Siddiquee [45] lists some examples of contemporary innovations such as citizen's charter, one-stop service delivery system, annual performance agreement, outsourcing, public-private partnerships, and online service provision under e-government. Arfeen and Khan [46] identifies different types of PSI including new public management under management innovation, performance management 
International Journal of Managing Public Sector Information and Communication Technologies (IJMPICT)

Vol. 9, No. 4, December 2018

under accountability \& transparency innovation, contracting out or public-private partnerships under partnership innovation, and e-Government, e-Participation or e-Knowledge management under digital innovation.

Lawrence [47] observes that the proliferation of ICT and the invention of the Internet in the 1990s with huge potential of renovating government lead many countries to establish special programs to foster innovation with the power of digital. A survey of World Bank [36] identifies that the increasing pressure from the end of service receivers led the government to major ICT transformation. Studies also reveal some other factors including inefficiency in information management [48], the competition with the private sectors and the popularity of Internet-based social media [39]. Although private sector is much ahead than public sector in embracing ICT-led innovation, there are ample examples of such innovation in the public sector even in the developing countries $[49,50]$. A recent report of UNO reveals that the popular use of social media by the public sector organizations has widely encouraged e-Participation, e-Services, eAdministration and other sources of e-Communication by connecting citizens, providing better services to them and creating knowledge for innovations [7]. Many developing countries are striving to institutionalize the culture of innovation among the public sector officials. For example, the Bangladesh government's initiatives for the formation of innovation teams comprising of reform-minded officers in all government offices and the introduction of innovation fund to incubate cost-effective ICT-led innovation have attracted many innovation researchers [51].

Although many studies embark on innovation in the public sector, Osborne \& Brown [52] demonstrate that there is often a debate about its precise meaning. To clarify the debate, Gow [53] points out that a successful innovation must meet measurable goals. This concept of innovation indicators is also supported by other organizations and researchers [54, 55]. For example, Zaman's [56] study on the notion of public sector innovation argues that service process simplification (SPS), which enables government officials to simplify public service delivery system, is a simple method of assessing innovation because it contributes in the reduction of time, costs and number of visits (TCV). He contends that whether the innovation is digital or nondigital, at least one of the TCV parameters is to be complied for an initiative to be considered as public sector innovation.

\subsection{ISSUES OF ICT-UTILIZED KM TOWARDS ICT-LED INNOVATION}

Studies show that knowledge being a fundamental resource, its management itself is a key innovation process $[57,58]$. This argument is further supported by Hedburg [59] who observes that the discarding of obsolete knowledge and the embedding of new knowledge leads an organization towards innovation. Therefore, there has been a growing interest among policy makers and researchers in understanding the integration of ICT with knowledge management and innovation in the public sector $[60,61]$.

Although there is a huge advocacy for promoting this digital transformation, information system researchers challenge any ICT-driven e-development initiatives and suggest a broader look in which ICT can contribute to socio-economic development [62, 63]. Castells [64] argues that more and new digital ICTs will not necessarily improve the access to or the dissemination of knowledge. Heeks [10] points out that ICT applications in the development sectors are not always effective because in developing countries, where technologies, which are applied with 'e' mania have experienced at least one-third total failures and one-half partial failures. Therefore, he suggests for considering the contextual factors underlying in 'i-development', which implies information-centered, interconnected, indigenized and intermediated ICTs before initiating any 'e-development' projects. The success of ICT is also subject to the availability of several resources as echoed in the information chain theory developed by Duncombe \& Heeks [65]. This 
International Journal of Managing Public Sector Information and Communication Technologies (IJMPICT)

Vol. 9, No. 4, December 2018

theory postulates that access to information is meaningless and there cannot be any contribution of information for development until 'information chain' is fully exploited. They argue that people need four resources to real access to knowledge: data resource (availability of relevant data); economic resources (money, skills and the knowledge) to access data; social resources (motivation \& confidence) to access, assess and apply data; and action resources (money, skills \& technology) in order to take action and decision.

A review of research evidences indicates that there are several factors affecting ICT-driven knowledge management in the public sector. For example, the study of Cong et al. [66] discovers that the overall ICT application in knowledge management is largely dependent on cultural and organizational change. It is also supported by Yao et al. [67] who find that employee attitudes seriously affect knowledge sharing in the government offices. The investigation of Currie et al. [68] identifies political commitment to be a driving force for knowledge management initiatives. The lack of transformational leadership is viewed as a barrier by Amayah [69]. A study of Dawes et al. [70] finds bureaucracy which clouds the performance of public sector knowledge management. Chiem [71] discovers that the conception of loss of power among the government employees hinders ICT-KM initiatives. Gow [53] identifies some other factors for promoting any type of innovation in the public sector such as the existing culture of organizational learning, encouragement \& recognition; and the availability of innovation capacity, skills in innovation management, innovation fund, sufficient resources \& and organizational characteristics to innovate.

To foster ICT-centric innovation through ICT-led knowledge management, Young [72] suggests the promotion of the culture of open data and open communications among all stakeholders. Hanna [73] also highlights the creation of an enabling environment which includes knowledge networks at different levels, and capacity building of human resource for accelerating such innovations.

\subsection{SUMMARY}

The review of literature critically analyzes the relevant theories and the latest findings to understand the knowledge gap. Studies reveal that with few exceptions, ICT can create, store and share both tacit and explicit knowledge. Research findings also exemplify that ICT can also be tapped for building knowledge networks through socialization, externalization, combination and internalization of knowledge. ICT-utilized knowledge management can thus foster ICT-led innovation by saving resources and bringing organizational benefits. However, there are several factors that hinder the ICT-mediated initiatives. From the review of literature, it is evident that there have been no studies accomplished so far in understanding the effect of ICT-utilized knowledge management to foster digital innovation in the public sector in a developing country.

\section{Methodology}

The study adopted a multiple case-study approach to investigate ICT-led innovation through ICTutilized knowledge management. Four organizations were considered as cases on the basis of their involvement in ICT-KM and ICT-I, especially developed for the study. The main aim of this paper is to investigate how the integration of ICT with knowledge management promotes ICTbased innovation in the context of Bangladesh public sector.

Yin [74] suggests that case study methodology is primarily based on interview, together with various sources of evidences. Since there was limited previous research on ICT's involvement in knowledge management in the public sector, an inductive approach using semi-structured interviews to generate qualitative data seemed to be suitable [75]. It enabled the researcher to gain in-depth views and experiences of individuals. It was also recognized that it was important to 
International Journal of Managing Public Sector Information and Communication Technologies (IJMPICT)

Vol. 9, No. 4, December 2018

provide respondents with the option to express their understanding of the issues regarding ICTutilized knowledge management leading towards ICT-led innovation in their work places. Under this backdrop, the qualitative research design was adopted to generate in-depth insights. Primary data were collected through in-depth semi-structured interviews. Other than interviews, this study used diverse data sources including participant observation, document analysis, and site visits. The job roles of the interviewees are shown in Table 1.

Table 1: Job roles of the interviewees

\begin{tabular}{|c|c|c|}
\hline Cases & Case organizations & Job roles \\
\hline Case A & Ministry of Public Administration & $\begin{array}{lc}\text { 1. } & \text { Head of Career Planning } \\
\& & \text { Training } \\
\text { 2. } & \text { Chief Innovation Officer } \\
\text { 3. } & \text { Senior Systems Analyst }\end{array}$ \\
\hline Case B & $\begin{array}{ll}\text { Bangladesh Civil } & \text { Service } \\
\text { Administration Academy } & \end{array}$ & $\begin{array}{l}\text { Chief Innovation Officer } \\
\text { Director (ICT) } \\
\text { Director (Training) }\end{array}$ \\
\hline Case C & $\begin{array}{lll}\text { Directorate } & \text { General } & \text { Health } \\
\text { Services } & & \\
\end{array}$ & $\begin{array}{ll}\text { 1. } & \text { Director (MIS) } \\
2 . & \text { Innovation Officer }\end{array}$ \\
\hline Case D & $\begin{array}{l}\text { Office of Deputy Commissioner, } \\
\text { Rajshahi district }\end{array}$ & $\begin{array}{ll}\text { 1. } & \text { Head of } \\
\text { Implementation } \\
\text { 2. } & \text { Chief Innovation Officer } \\
\text { 3. } & \text { Policy Advisor } \\
\text { 4. } & \text { Innovation Officer }\end{array}$ \\
\hline
\end{tabular}

A total of twelve semi-structured interviews were conducted with twelve respondents who have somehow a direct or an indirect connection with ICT-based KM and ICT-led innovation in the public sector in Bangladesh. An interview schedule was designed and piloted. Potential respondents were identified through preliminary meetings with the officials concerned in each organization.

The questions in the interview schedule are:

1. What are the criteria of ICT-led innovation in the public sector in Bangladesh?

2. What are the key ICTs that your organization utilizes for managing knowledge?

3. Does your organization promote ICT-led innovation through ICT-mediated knowledge management? If yes, how?

4. How does your organization manage tacit and explicit knowledge through ICT?

5. What are the factors that affect ICT-mediated knowledge management in your organization?

The interviewees were formally contacted to get their approval to interview them. Before the start of the interview, each respondent was provided with information of the research area. Each interview lasted between 30 to 45 minutes. The permission to record interviews was obtained. All the interviews were transcribed into Microsoft Word that facilitated the researcher to send the transcripts to the respondents for making amendments, if required.

Thematic analysis of the transcripts was made in three stages, as guided by the themes identified in the interview schedule. Transcripts were first analyzed individually to identify the key themes in each case organization. Then the common themes among the interviewees within one case organization were identified. Finally, a comparison was made across the analyses of the case organizations to surface out general conclusions on ICT-led innovation through ICT-utilized knowledge management. 
International Journal of Managing Public Sector Information and Communication Technologies (IJMPICT)

Vol. 9, No. 4, December 2018

\section{Profiles of Case Organizations}

\section{Case A: Ministry of Public Administration (MOPA)}

MOPA is the largest ministry of the government of Bangladesh. The core functions of this regulatory ministry include the recruitment, promotion, posting \& training of Bangladesh civil servants; and the formulation of rules \& regulations to run the public administration. MOPA has over 5000 civil servants and over 6000 employees under its field administration category in eight administrative divisions, 64 districts and 490 sub-districts. It has also seven directorates under its direct supervision. The top management team comprises the Minister, State Minister, Senior Secretary and other key officials. MOPA uses website, e-learning, e-file, e-library, personnel management information system which have knowledge management components.

\section{Case B: Bangladesh Civil Service Administration ACademy (BCSAA)}

BCSAA, an attached department of MOPA, is a core training institute for the members of Bangladesh Civil Service (Administration) cadre officers. Since its inception in 1987, BCSAA has offered 275 long and short courses and trained about 8000 officers. It has 125 personnel of different ranks and positions. The head of this organization is the Rector who is also a senior civil servant. E-Learning platform is the main knowledge management initiative at BCSAA. This tool stores training-related materials and links to relevant knowledge-base for the participants and the faculty members.

\section{Case C: Directorate General Health Services (DGHS)}

DGHS is the largest implementing authority of healthcare under the ministry of health and family welfare. It provides technical assistance to the ministry in undertaking new programs and interventions. It has over one hundred thousand officers and staff members. The top management includes director general and other officials. DGHS's six tiers healthcare-delivery system is extended from national to the community-level. The most important area of ICT-KM is the use of video conferencing system which facilitates the dissemination of tacit knowledge through emeeting with the field-level officials.

\section{CASE D: OfFice OF THE DEPUTy COMMissioner, RAJShaHi District}

Office of the Deputy Commissioner, Rajshahi District is a typical organization at the field administration which represents the central government at the district level. It is overall responsible for overseeing all the general matters, coordinating the development work, maintaining law and order, collecting revenue and administering land-related matters. Deputy Commissioner is the chief executive officer of the district. There are huge applications of ICT$\mathrm{KM}$ including social media and other Online tools for KM.

\section{FINDINGS}

This section summarizes the key findings which are structured under the following key headings: perception of ICT-led innovation; practices of ICT-led innovation through ICT-utilized knowledge management; and factors affecting knowledge management through ICT. To create vigor to the analysis, the quotes from the collected data have been used where applicable.

\subsection{DIGITAL INNOVATION THROUGH ICT-KM}

The findings revealed that ICT-led digital innovation in the public sector in Bangladesh takes place when digital technologies save resources of the government offices through capturing, 
International Journal of Managing Public Sector Information and Communication Technologies (IJMPICT)

Vol. 9, No. 4, December 2018

accessing, storing, and disseminating knowledge. These experiences of ICT-KM were shared by the officials of the organizations under study, i.e. Ministry of Public Administration, Directorate General of Health Services, Bangladesh Civil Service Administration Academy, and Office of the Deputy Commissioner, Rajshahi district.

It was observed that all of these offices have the applications of e-mail, web portals, e-filing, social media and video conferencing system which enable them to best utilize ICT to capture, store or share knowledge. For example, they use social media page and website for both the citizens and government employees who can share and upload the social problems to be solved immediately by the officials concerned. The innovative use of social media by the government officers is linked to their annual performance. The findings also revealed that the government servants solve many social and community problems through engaging a huge number of online followers within a short time which is not possible in the traditional governmental system.

The innovation officer in Case $\mathrm{C}$ comments:

Government has instructed us to create social media pages to share our service information with the community. Our social media group is being used to hear from the service-receivers about their problems and to provide them rapid response by tagging the officials concerned for solutions.

The respondents admitted that for capturing, accessing, storing and sharing both tacit and explicit knowledge, the extensive use of open-sourced Online tools can transform the knowledge management practices of the public offices by saving resources and enhancing efficiency. Findings also indicated that these public offices have improved their knowledge management experience than before. It has not only reduced time, cost and movement of its clients, but also enhanced the organizational efficiency to a great extent.

The Chief Innovation Officer in Case A states: ICT-KM triggers innovation. We may term such innovations as ICT-led innovations because they focus on how e-Government can be best utilized in the creation, storage, dissemination and application of knowledge. Apparently, public sector has tremendous opportunities for leveraging knowledge management which can redefine ICT innovation.

Apart from explicit knowledge, public sector organizations can play a challenging role in managing its invaluable tacit knowledge. The Chief Innovation Officer in Case D comments:

ICT-KM can accumulate intellectual capital which is the total of an organization's knowledge. By extracting all the knowledge from every employee, we can store a huge amount of intellectual capital. The experiences of retiring staff can be saved....ICT does not let knowledge to be lost.

All the respondents agreed that ICT-utilized knowledge management can increase ICT-led innovation through saving time, cost and movement of the clients in receiving an information or gaining a piece of knowledge that enhances the efficiency of the government machinery.

Director (ICT) of Case B mentioned: Knowledge management through ICTs at BCSAA is of great importance to us because we are mandated to manage existing knowledge, create new knowledge, store and share the knowledge base with the existing and potential participants who are in serious need of such insightful knowledge of experienced civil servants. We often use simple and available ICT tools to capture tacit knowledge of our resource persons. For example, we make audio or video record of the lectures, edit the recorded files and upload them in our e-Learning platform or in popular social media which are widely used by our potential participants at the field-level.

However, findings revealed that both the ICT-utilized knowledge management and ICT-led innovation are at the primary stage in the public offices. Overall, respondents agreed that several 
International Journal of Managing Public Sector Information and Communication Technologies (IJMPICT)

Vol. 9, No. 4, December 2018

ICT interventions in knowledge management were employed to foster ICT-led innovations in government offices.

\subsection{Perception Of ICT-Led InNovation}

The findings revealed that ICT-led innovation in the public sector is the extension of innovation that uses ICT or the Internet or other digital technologies to reduce time, cost and number of movements of the service receiver. Such innovations should have the measuring criteria with its capacity to save time, cost and movements (TCM) in creating, accessing, storing and disseminating knowledge. According to the respondents, the digital/electronic or ' $\mathrm{e}$ ' phenomenon is often prefixed with the core functionalities of the government, e.g. e-Government, eAdministration, e-Knowledge management, e-Learning, e-Communication, e-Participation, eService, e-Consultancy and so on.

Respondents added some other criteria including the enhancement of the capacity of public sector employees, improved organizational performance and knowledge-based community. According to most of the respondents, ICT-led innovation is fostered when ICTs add value in the overall performance of the government offices through saving resources, creating knowledge networks \& intellectual capital, improving decision-making process, and changing behavior. It is ultimately countable in terms of saving time, cost and movement of the government officials who want to create, collect, store and share a particular knowledge or information.

The Innovation Officer of Case D stated: ICT can be innovatively utilized for the conversion of tacit knowledge into explicit knowledge as e-Learning or e-KM or e-Capacity development or any other electronic nomenclatures. This task can transform the public offices through strategic use of knowledge.

All the respondents attempted to define ICT-led innovation, but topping the list was the perception of 'Time, cost \& movement-saving', mentioned by most of the respondents. The findings revealed two more sub-themes 'enhancement of capacity' and 'improved organizational performance' identified during the interview.

The comment of the Head of Policy Implementation in Case D below demonstrates the perception of ICT-led innovation from ICT-KM perspective:

'ICT-led innovation' takes place when ICT enhances innovation. Web pages of the public offices that disseminate explicit information to its clients and e-filing system that converts government officials' tacit knowledge to explicit knowledge are examples of ICT-KM in the context of Bangladesh public sector.

Overall, from knowledge management perspective, the respondents view ICT-led innovation as any ICT-rendered service that reduces time, cost and movement (TCM) of individuals in creating, accessing, storing or disseminating a piece of knowledge.

\subsection{Factors Affecting Knowledge Management Through ICT}

The respondents identified several factors which are responsible for the success and failure of knowledge management through ICT. The most important factor is institutional, which indicates that the concept of knowledge management in the public sector itself is in infancy. Therefore, it is often difficult to grasp how ICT can be tapped into exploiting tacit and explicit knowledge in government organizations. Among other issues under institutional factor are the leadership role, political commitment, vision \& strategy and availability of ICTs. 
International Journal of Managing Public Sector Information and Communication Technologies (IJMPICT)

Vol. 9, No. 4, December 2018

According to the Chief Innovation Officer in Case B: In fact, we are at the initial stage of ICT use in public sector knowledge management. We expect to do better in the years to come. However, any application of ICT should be strongly meant by the government. If there is huge demand of ICT-KM both in the tacit and explicit domains, the public officials will be more encouraged to create, store, retrieve and disseminate knowledge through ICTs. This drive will in turn lead to more ICT-led innovations in the public sector.

Respondents suggested an effective knowledge management strategy and action plan. Although government has the National ICT Policy 2014, the public sector organizations need to have a complete ICT innovation policy that should focus more on ICT-centric knowledge management in the government offices. Respondents contended that the failure to do so is due to the lack of leadership role and government initiatives towards a comprehensive policy and guidelines for coupling ICT-KM and ICT-I. They also mentioned the traditional mindset and fear of change of senior officials are other reasons of failure. According to the respondents, technology is not always a barrier, if the strategic leadership role and strong political commitment are there.

Director (Training) in Case B comments:For ICT interventions in public sector knowledge management, technology and financial matters are not key issues. There are many contemporary tools and technologies. A clear guideline on the use of these tools and technologies including awareness on using them in public sector management can foster ICT innovation and enhance the capacity of government officials.

The respondents observed that some government officials are reluctant to understand the potential of managing and exploiting knowledge by the help of ICTs. Their conception about generating and sharing knowledge through knowledge processes is not fully clear. As observed from the case organizations, ICT has made a lot of changes in the e-services, but it has not been fully exploited in managing knowledge particularly in e-Administration domain. It is caused by the shortcoming of government offices in initiating knowledge management culture. So, the absence of such atmosphere of promoting knowledge-based ICT-innovation is another reason of the missing administrative leadership. Organizational culture is another factor that hinders the promotion of ICT innovation through ICT-mediated knowledge management. Respondents apprehended that government officials are not often inclined to share their tacit knowledge through ICTs because they have the fear that sharing personal knowledge will weaken their power and authority.

Next to the institutional perspective, resource category lists some important factors including human, financial and technological standpoints. It is in reality that the lack of skills and capabilities within the government system exposes any ICT initiative in vulnerability. The respondents identified that the lack of skilled IT professionals hinders success. The policy advisor in Case D is of the opinion that the lack of motivation of the public sector employees restricts ICT intervention in knowledge management. There is a pre-conception that only information technology (IT) department will accomplish any ICT-related innovation. The main problem that was observed by most of the respondents indicates that IT personnel does not often know how to solve a business problem with ICT. Since they are technical staff, the generalists often view that IT department is separated from the main stream of the organization. The head of career planning and training in Case A suggests that before initiating any knowledge exploiting initiatives, the readiness of the government staff is inevitable. According to the respondents, the main drawback is the lack of proper management and absence of plans for the sustainability of any ICT project or initiative. Human resource was perceived to be the most crucial factor for successful ICT-KM followed by financial and technological issues.

The success of ICT is also subject to the availability of several access factors. Respondents observed that for the implementation of ICT-KM initiatives, the government employees need to have real access to knowledge. They also mentioned money, skills and technology are required to 
International Journal of Managing Public Sector Information and Communication Technologies (IJMPICT)

Vol. 9, No. 4, December 2018

access to ICT-utilized knowledge. Findings also revealed that employees' motivation and confidence are also necessary for assessing and applying knowledge in order to take decision. Two other sub-themes under access factor are 'motivation \& confidence' and 'money \& skills'. It is apparent that lack of awareness is the main reason for the obstacle to ICT-KM.

It was observed that there are variations of the application of ICT-KM among different government offices due to their varying nature of functioning. Some organizations are efficient while some organizations are lagging behind. This variation is mainly due to the different nature of work and differences in leadership role, budgetary allocation and capacity to innovate.

\section{DISCUSSION}

The findings of this study contribute significantly to a better understanding of ICT's integration with knowledge management and its influence on the promotion of Internet-based digital innovation in the public sector in Bangladesh. This section offers a comprehensive discussion of the results of this study by comparing the major findings to the literature.

The most important finding from this study denotes that ICT's intervention for capturing, accessing, storing and transferring tacit \& explicit knowledge positively influence digital innovation in the public sector. This corresponds to the existing literature that reveals ICT's intrinsic role to create value in terms of saving resources through its capacity to manage knowledge [13, 24]. The ideas of Alavi and Leidner [3], who develops a framework of ICT applications for knowledge management is also matching with this result. The respondents state that digital knowledge management adds value in the overall performance of public offices through the creation of social knowledge networks and intellectual capital, which is confirmed by Liebowitz and Frank [6]. Most of the respondents agree with Min [30] that ICT-based knowledge management can improve decision-making process, change behavior of the employees, utilize resources and improve efficiency in the public sector.

The findings also reveal that ICT-led innovation is best reflected through its measuring capacity. It suggests that such innovation is quantifiable in terms of money through reducing time, cost and movement (TCM) to receive any particular information or knowledge. This finding is consistent with the recent studies in the literature that consider ICT-led innovation as crucial for digital government $[49,61]$. The possible explanation for this result is that the key knowledge management functions, i.e. knowledge creation, knowledge storage and knowledge sharing when coupled with ICTs, can only be called as 'ICT-led innovations' if they can contribute to saving time, cost and movement for the tacit and explicit knowledge users. The TCM parameters are thus the determining factors for such innovations. Another interpretation of these three measuring criteria is that either one of the criteria must be measurable, if any ICT-KM initiative need to be considered as digital innovation. This finding of TCM parameter is clearly consistent with that of Gow [53], who argues that an innovation should have measurable goals. The respondents also hold the view of Zaman [56] that a simple method of assessing any digital or non-digital innovation is the capacity of that innovation to generate some utilities for the service recipient. Based on this finding ICT-led innovation in various public sector organizations is evident through this TCM parameter. It means that public sector ICT applications through e-Services, eAdministration and e-Participation have been proved time-reducing, cost-saving and movementrelieving. The respondents of the study also showed that they find TCV-saving criteria easy to use to implement any digital innovation.

The findings also reflect that the main barrier of ICT-based knowledge management initiatives is the lack of awareness of the government officials about the innovative uses of ICT. This finding is also important because it has significant impact on the ICT-led digital innovation. In tune with Amayah [69], the respondents assert that the high officials, being the main driving force, need to 
International Journal of Managing Public Sector Information and Communication Technologies (IJMPICT)

Vol. 9, No. 4, December 2018

have clear understanding of how knowledge can be captured, shared, stored and applied with ICTs. The respondents viewed that this institutional factor can seriously influence innovative uses of ICT for managing knowledge.

In summary, the findings show a clear understanding of the influence of ICTs to foster digital innovation; the role of the TCM parameters to measure this innovation and the factors that can significantly impact on the applications of ICT in knowledge management and innovation in the public sector.

\section{CONCLUSIONS AND RECOMMENDATIONS}

This paper investigates how ICT-utilized knowledge management initiatives are promoted towards Internet-based digital innovation. It offers a range of insights into the integration of ICT with knowledge and innovation in the context of Bangladesh public sector. This is the first study on the areas of development informatics. This paper has three major contributions by filling the knowledge gaps: First, it shows new knowledge about how ICTs influence digital innovation; Second, it devised out a new TCV model to measure the impact of any ICT-mediated innovation; Third, it discovered the driving forces that positively impact on ICT-based knowledge management. The findings have also important practical implications for the government decision-makers, who have been using ICT for managing knowledge for many years. However, no studies were undertaken so far to understand the key issues linking KM and innovation in a digital environment.

There are three key limitations to the research findings. First, in the public sector in Bangladesh, there are many organizations which have knowledge management activities through ICTs. Since this study considered only four organizations, and data were collected from a limited number of officials, the findings cannot be generalized to other public sector employees. As a result, recommendations from this study may vary in different contexts. Second, this qualitative case study research in absence of statistical inferences relied on inferences to make analytical generalizations based on perceptions of the respondents at a particular point of time. Therefore, it may be subject to bias. Third, the sample of cases for this study could be drawn from other developing countries or from different sector contexts with different cultures or sub-cultures. It could have enriched the generalizability of the findings.

This paper depicts a picture of Bangladesh's public sector organizations, which are quite aware of ICT-led innovation and much advanced in delivering public services through ICT. It is evident that this matter is of concern to these organizations. However, there are no strategies or guidelines for managing knowledge through ICT. As a result, there is no planned approaches and remarkable initiatives in ICT-KM. Furthermore, there is a consensus that existing initiatives are very limited due to the institutional factors including lack of awareness, leadership role and unclear idea about ICT's integration with knowledge management and innovation.

On the basis of the findings in this study, we suggest the following recommendations:

The leadership role needs to develop ICT-utilized knowledge management strategies and consider how the access, creation, storage and dissemination of tacit and explicit knowledge through digital technologies can contribute to the slow process of cultural change and create an enabling environment for ICT-led innovation.

On the basis of the strategies developed for promoting ICT-led innovation through ICT-utilized knowledge management, several organizational conventions need to be abolished. For example, sudden transfer of officials in charge of ICT-related matters creates a vacuum which cannot be 
International Journal of Managing Public Sector Information and Communication Technologies (IJMPICT) Vol. 9, No. 4, December 2018

compensated instantly. Therefore, the government should take measures to address these practices.

The government should promote the culture of 'knowledge worker' in its policy on ICT-based knowledge management. It should emphasize more on knowledge along with ICT's capacity to serve citizens through e-Service. It will enable the government officials to realize that knowledge management is a core function of ICT. In order to enhance the capacity of public sector employees, it will pave the avenues for better utilization of human resource capacity development under e-Administration component of e-Government.

The aim of this study was to investigate the impact of ICT-utilized knowledge management on ICT-led innovation in the public sector in Bangladesh. There is still scope for further research in the areas of ICT's integration with knowledge management. Specifically, the study suggests the following areas for undertaking future research:

- The influence of ICT-utilized knowledge management on the performance of public sector employees.

- The integration of tacit and explicit knowledge through ICTs;

- The effects of the factors critical for ICT-based knowledge management;

- ICT-based knowledge management through encompassing both citizens and government employees to understand a macro-view;

- ICT-utilized knowledge management in other public sector organizations which are less ICT-intensive compared to the case organizations.

In general, this study offers a useful basis for further research into ICT's intervention in knowledge management for fostering ICT-led innovation in the public sector. Since the understanding of the power of ICT is apparently partial among the government officials, tapping ICT or digital technologies for managing knowledge to turn these initiatives into ICT innovations is often absent. Furthermore, the lack of proper leadership role \& resources and the impact of socio-cultural factors hinder any ICT-led innovation.

\section{REFERENCES}

[1] Barua, M. (2012), "E-Governance Adoption in Government Organization in India", International Journal of Managing Public Sector Information and Communication Technologies (IJMPICT), Vol. 3 No. 1.

[2] Sousa, M.J. and Rocha, A. (2019), "Strategic Knowledge Management in the Digital Age: JBR Special Issue Editorial”, Journal of Business Research, Vol. 94, pp. 223-226.

[3] Alavi, M. and Leidner, D.E. (2001), "Knowledge Management and Knowledge Management Systems: Conceptual Foundations and Research Issues”, MIS Quarterly, Vol. 25 No. 1, pp. 107-136.

[4] Dawes, S.S. and Gharawi, M.A. (2018), "Transnational Public Knowledge Networks: A Comparative Study”, Government Information Quarterly, Vol. 35 No. 2, pp. 184-194.

[5] McNabb, D.E. (2007), Knowledge management in the public sector: A blueprint for Innovation in Government. ME Sharpe, London.

[6] Liebowitz, J. and Frank, M. (2011), Knowledge management and e-learning (Ed.), Taylor \& Francis Group, New York.

[7] United Nations Organization (2017), United Nations E-government Survey 2017, United Nations Organization (UNO), New York.

[8] Maravilhas, S. and Martins, J. (2019), "Strategic Knowledge Management in a Digital Environment: Tacit and Explicit Knowledge in Fab Labs”, Journal of Business Research, Vol. 194, pp. 353-359.

[9] Kasim, H.A. (2015), "Using Virtual Platforms - A Validation of Unified Theory of Acceptance and Use of Technology (UTAUT)", International Journal of Managing Public Sector Information and Communication Technologies (IJMPICT), Vol. 6 No. 2.

[10] Heeks, R.B. (2005), Foundations of ICTs in Development: The Information Chain, eDevelopment Briefing No. 3, Center for Development Informatics, University of Manchester, UK. 
International Journal of Managing Public Sector Information and Communication Technologies (IJMPICT)

Vol. 9, No. 4, December 2018

[11] Polanyi, M. (1962), Personal Knowledge: Towards a Post-Critical Philosophy, Harper Torchbooks, New York.

[12] Polanyi, M. (1967), The Tacit Dimension, Routledge, London.

[13] Nonaka, I. (1994), A Dynamic Theory of Organizational Knowledge Creation, Organization Science, Vol. 5 No. 1, pp. 14-37.

[14] Davenport, T. H., and Prusak, L. (1998), "Working Knowledge: how organizations manage what they know", Harvard Business School Press, Boston.

[15] Blackler, F. (1995), "Knowledge, knowledge work and organizations: an overview and interpretation”, Organization Studies, Vol. 16 No. 6, pp. 1021-1046.

[16] von Krogh, G. (1998), "Care in Knowledge Creation”, California Management Review, Vol. 40 No. 3, pp. 133-153.

[17] Nonaka, I. and Takeuchi, H. (1995), The Knowledge Creation Company: How Japanese Companies Create the Dynamics of Innovation, Oxford University Press, New York.

[18] Frach, L., Fehrm, T. and Pfonnes, P. (2017), "Measuring Digital Government: How to Assess and Compare Digitalization in Public Sector Organizations", in Falk, S. Rommele, A. and Silverman, M. (Ed.), Digital Government: Leveraging Innovation to Improve Public Sector Performance and Outcomes for Citizens, Springer, New York.

[19] Panir, J.H. (2011), "Role of ICTs in the Health Sector in Developing Countries: A Critical Review of Literature", Journal of Health Informatics in Developing Countries, Vol. 5 No. 1.

[20] Heeks, R.B. (2002), i-Development not e-Development: Special Issue on ICTs and Development, Journal of International Development, Vol. 14 No. 2, pp. 1-11.

[21] Bellamy, C. (2003), "Moving to e-Government: The role of ICTs in the public sector", in Bovaird T. and Loffler, E. (Ed.), Public Management and Governance, Routledge, London, pp. 113-25.

[22] Daft, R.L. (2004), Organization Theory and Design. (8th ed.), Thomson, Ohio.

[23] Hansen, M.T., Nohria, N. and Tierney, T. (1999), "What's Your Strategy for Managing Knowledge?", Harvard Business Review, March-April, pp. 106-116.

[24] Tessier, D. and Dalkir, K. (2016), "Implementing Moodle for e-learning for a successful knowledge strategy", Knowledge Management \& E-Learning, Vol. 8 No. 3, pp. 414-429.

[25] Holzner, B. and Marx, J. (1979), The Knowledge Application: The Knowledge System in Society. Allyn-Bacon, Boston.

[26] Lau, A. and Tsui, E. (2009), "Knowledge management perspective on e-learning effectiveness", Knowledge-Based Systems, Vol. 22.

[27] Bonifacio, R., Franz, T. and Staab, S. (2008), “A four-layer model of information technology support of knowledge management", in Becerra-Fernandez, I. and Sabberwa, R. (Ed.), Knowledge Management: An Evolutionary View, ME Sharpe, New York.

[28] Wild, R.H., Griggs, K.A. and Downing, T. (2002), "A framework for e-learning as a tool for knowledge management", Industrial Management and Data Systems, Vol. 102 No. 7, pp. 371-380.

[29] Kim, S. and Lee, H. (2006), The impact of organizational context and information technology on employee knowledge sharing capabilities", Public Administration Review, Vol. 66 No. 3, pp. 370385.

[30] Min, L.G.P.J. (2017), “Employees' online knowledge sharing: the effects of person-environment fit”, Journal of Knowledge Management, Vol. 21.

[31] Ministry of Public Administration (2016), E-learning for Bangladesh Civil Service: From Vision to Implementation, Ministry of Public Administration, Government of Bangladesh, Dhaka.

[32] Seba, I. and Rowley, J. (2010), "Knowledge management in UK police forces", Journal of Knowledge Management, Vol. 14 No. 4, pp. 611-629.

[33] Cabinet Division (2016), Use of Social Media for Innovations, Government of Bangladesh, Dhaka.

[34] Bransford, J. (1998), "Designing environments to reveal, support and expand our children's potentials", in Sloraci, S. and McIlvane, W. (Ed), Perspectives on Fundamental Processes in Intellectual Functioning, Ablex Publishing, New York.

[35] Hao, X., Zheng, D., Zeng, Q. and Fan, W. (2016), "How to strengthen the social media interactivity of e-government: Evidence from China", Online Information Review, Vol. 40 No. 1, pp. 79-96.

[36] World Bank (2010), Innovation Policy: A Guide for Developing Countries, World Bank, Washington DC.

[37] Khin, S. and Ho, T.C. (2018), "Digital Technology, Digital Capability and Organizational Performance: A Mediating Role of Digital Innovation”, International Journal of Innovation Science, Nov. 
International Journal of Managing Public Sector Information and Communication Technologies (IJMPICT)

Vol. 9, No. 4, December 2018

[38] Chowdhury, A. and Beresford, N. (2016), "How a2i is using empathy to foster innovation in Bangladesh", available at http://blogs.lse.ac.uk/southasia/2017/02/06/how-a2i-is-using-empathy-tofoster-innovation-in-bangladesh/ (accessed 3 October 2018).

[39] Walsh, C.S., Woodward, C. and Shrestha, P. (2015), "The potential of Mobile Phones to Transform Teacher Professional Development to Build Sustainable Educational Futures in Bangladesh", Asian Association of Open Universities Journal, Vol. 10 No. 1.

[40] Chowdhury, A., Hambly, H., Thomson, S. and Hauser, M. (2015), "Enhancing farmers' capacity for botanical pesticide innovation through video-mediated learning in Bangladesh", International Journal of Agricultural Sustainability, Vol. 5 No. 2.

[41] Kanter, R.M. (1998), "When a Thousand Flowers Bloom: Structural, Collective and Social Conditions for Innovation in Organizations", in Staw, B. M. and Cummings, L.L. (Ed.), Research in Organizational Behavior, JAI Press, Greenwich, pp. 169-211.

[42] Mullins, M. E., Kozlowski, S. W. J., Schmitt, N. and Howell, A. W. (2008), "The Role of the Idea Champion in Innovation: The Case of the Internet in the Mid-1990s", Computers in Human Behavior, Vol. 24 No. 2, pp. 451-467.

[43] Glor, E.D. (1992), "Promoting Innovations in the Public Sector", Public Productivity and Management Review", Vol. 16 No. 2, pp. 157-171.

[44] Osborne, S. P. (1998), "Naming the Beast. Defining and Classifying Service Innovations in Social Policy”, Human Relations, Vol. 51 No. 9, pp. 1133-1154.

[45] Siddiquee, N. (2008), "Service delivery innovations and governance: the Malaysian experience", Transforming Government: People, Process and Policy, Vol. 2 No. 3, pp. 194-213.

[46] Arfeen, M. I. and Khan, N. (2009), "Public Sector Innovation: Case Study of e-government Projects in Pakistan", The Pakistan Development Review, Vol. 48 No. 4, pp. 439-457.

[47] Lawrence, C. (2013), "Innovating with Information Technology in a Globalized World - Being Proactive about Culture", PhD Dissertation. University of Oulu, Finland.

[48] Rashid, N. (2011), "e-Government as a Tool to Promote Transparency and Openness: The Case of Bangladesh", PhD Thesis, Monash University, Victoria.

[49] Kankanhali, A. Zuiderwijk, A. and Tayi, G.K. (2017), "Open innovation in the public sector: A research agenda,", Government Information Quarterly, Vol. 34 No. 1. Pp. 84-89.

[50] Siddiquee, N. (2016), "E-government and transformation of service delivery in developing countries: the Bangladesh experience and lessons", Transforming Government: People, Process and Policy, Vol. 10 No. 3.

[51] Prime Minister's Office (2018), Putting Citizens First, Prime Minister's Office, Dhaka.

[52] Osborne, S. P. and Brown, L. (2011), "Innovation, Public Policy and Public Services: The Word that Would be King?”, Public Administration, Vol. 89 No. 4, pp. 1335-1350.

[53] Gow, J.I. (2014), "Public Sector Innovation Theory Revisited", The Innovation Journal: The Public Sector Innovation Journal, Vol. 19 No. 2.

[54] Chae, B. (2019), "A General Framework for Studying the Evolution of the Digital Innovation Ecosystem: The Case of Big Data", International Journal of Information Management, Vol. 45 (Apr), pp. 83-94.

[55] European Commission (2011), Innobarometer 2010: Innovation in Public Administration. EC, Brussels.

[56] Zaman, H. (2015), Service delivery process innovation: insights from Digital Bangladesh, Innovation and Development, Vol. 5 No. 1: 165-168.

[57] Sindakis, S., Depeige, A. and Anoyrtati, E. (2015), "Customer-tentered knowledge management: challenges and implications for knowledge-based innovation in the public transport sector", Journal of Knowledge Management, Vol. 19 No. 3.

[58] Wallace, R.B. (2010), "The Relationship of Organizational Learning to Knowledge Management and its Impact on Innovation”, PhD Dissertation, Michigan Technological University, Michigan.

[59] Hedberg, B. (1981), How Organizations Learn and Unlearn: Handbook of Organizational Design, Oxford University Press, Oxford.

[60] Vrontis, D. Thrassou, A. and Dezi, L. (2018), "The Internet of Things: Building a knowledge management system for open innovation and knowledge management capacity”, Technological Forecasting and Social Change, Vol. 136 (Nov), pp. 347-354.

[61] Paskalva, K and Cooper, I. (2018), "Open innovation and the evaluation of Internet-enabled public services in smart cities", Technovation, Vol. 78, pp. 4-14.

[62] Heeks, R.B. (2010), "Do Information and Communication Technologies (ICTs) Contribute to Development?", Journal of International Development, Vol. 22, pp. 625-640. 
International Journal of Managing Public Sector Information and Communication Technologies (IJMPICT)

Vol. 9, No. 4, December 2018

[63] Bhatnagar, S. (2004), E-Government: From vision to Implementation, Sage, New Delhi.

[64] Castells, M. (1989), The informational city: information technology, economic restructuring and the urban-regional process, Blackwell, Oxford.

[65] Duncombe, R. and Heeks, R.B. (2002), "Enterprise across the Digital Divide: Information Systems and Rural Micro-enterprise in Botswana", Journal of International Development, Vol. 14 No. 1, pp. 61-74.

[66] Cong, X., Li-Hua, R. and Stonehouse, G. (2007), "Knowledge management in the Chinese public sector: empirical investigation", Journal of Technology Management in China, Vol. 2 No. 3, pp. 250263.

[67] Yao, L.J., Kam, T.H.Y. and Chan, S.H. (2007), "Knowledge sharing in Asian public administration sector: the case of Hong Kong”, Journal of Enterprise Information Management, Vol. 20 No. 1.

[68] Currie, G., Waring, J., and Finn, R. (2008), "The limits of knowledge management for UK public services modernization: The case of patient safety and service quality", Public Administration, Vol. 86 No. 2, pp. 363-385.

[69] Amayah, A.T. (2013), "Determinants of knowledge sharing in a public sector organization", Journal of Knowledge Management, Vol. 17 No. 3, pp. 454-471.

[70] Dawes, S.S., Cresswell, A.M. and Pardo, T.A. (2009), "From 'need to know' to 'need to share': Tangled problems, information boundaries, and the building of public sector knowledge networks", Public Administration Review, Vol. 69 No. 3, pp. 392-402.

[71] Chiem, P.X. (2001), "In the public interest: government employees also need incentives to share what they know", Knowledge Management Magazine, August.

[72] Young, J. (2012), Personal Knowledge Capital: The Inner and Outer Path of Knowledge Creation in a Web World, Chandos Publishing: Oxford.

[73] Hanna, N.K. (2011), Transforming Government and Building the Information Society: Challenges and Opportunities for the Developing World, Springer, London.

[74] Yin, R.K. (1989), Case Study Research - Design and Methods, Sage, Beverly Hills.

[75] Boyatzis, R. (1998), Transforming qualitative information: Thematic analysis and code development, Sage Publications, Thousand Oaks. 